\title{
Comparing the European Union System for the Evaluation of Substances (EUSES) environmental exposure calculations with monitoring data for alkyl sulphate surfactants
}

Oliver Spaniol ${ }^{1}$, Marlies Bergheim², James Dawick ${ }^{3}$, Denise Kötter ${ }^{4}$, Kathleen McDonough $^{5}$, Diederik Schowanek ${ }^{6}$, Kathleen Stanton ${ }^{7}$, James Wheeler ${ }^{8}$ and Andreas Willing ${ }^{9^{*}}$ (D)

\begin{abstract}
Background: The European surfactant and detergent industry initiated a project to conduct an EUSES-based environmental exposure assessment for the total volume of alkyl sulfate (AS) surfactants, and to verify if the EUSES assessment leads to a realistic prediction of the environmental exposure or to an over- respectively under-estimation of the environmental concentrations of the surfactants. Verification of the EUSES environmental concentration prediction $\left(\mathrm{Clocal}_{\text {effluent }}\right)$ was carried out by benchmarking them against environmental monitoring data. Recently published data from the United States of America adjusted to the European Union (EU) frame conditions were used for the assessment, as for the EU only historical data from the mid-1990s are available. In addition to the standard (default) EUSES assessment, a higher tier assessment using substance-specific properties, particularly increased biodegradation rates (192 per day instead of the default of 24 per day for WWTP), was conducted.
\end{abstract}

Results: A figure of 178,400 tonnes of AS was established as the total maximum volume (2016) handled annually in Europe. This total volume includes the volumes from all EU manufacturers and all registered AS $>100 \mathrm{t} / \mathrm{a}$, as well as the amount of AS contained in EU REACH registered alkyl ether sulfates (AES). The total tonnage was split and assigned to the different uses as reported to ECHA in the C12 AS, Na (151-21-3) registration dossier in 2010. The EUSES calculation was limited to widespread (professional and consumer) uses, covering in total 97,889 t of AS homologues. The EUSES calculation gave a Clocal effluent $_{\text {of }} 335 \mathrm{\mu g} / \mathrm{L}$ for the SimpleTreat "readily" biodegradation rate default and a $\mathrm{Clocal}_{\text {effluent }}$ of $44.6 \mathrm{\mu g} / \mathrm{L}$ for the AS-specific degradation rates. Recent US monitoring data showed a mean effluent concentration of $4.24 \mu \mathrm{g}$ alkyl sulfates $/ \mathrm{L}\left(\sum \mathrm{C} 12+\mathrm{C} 14+\mathrm{C} 16\right.$ homologues). Taking into account the different annual per capita AS use (including AS from AES) in the US (295 g) and the EU (348 g), the daily per capita water use (EU $200 \mathrm{~L}$, US 408 L), and the WWTP efficiency in the EU and the US (comparable), an US to EU adjustment factor of 2.4 was established. Application of the adjustment factor to the US monitoring data resulted in a calculated EU mean effluent concentration $=10.18 \mu \mathrm{g}$ alkyl sulfates $/ \mathrm{L}\left(\sum \mathrm{C} 12, \mathrm{C} 14, \mathrm{C} 16\right.$ homologues). This value was used as an independent benchmark for the EUSES calculations.

\footnotetext{
*Correspondence: andreas.willing@basf.com

${ }^{9}$ BASF Personal Care and Nutrition GmbH, Henkel Str. 67,

40589 Düsseldorf, Germany

Full list of author information is available at the end of the article
} in this article are included in the article's Creative Commons licence, unless indicated otherwise in a credit line to the material. If material is not included in the article's Creative Commons licence and your intended use is not permitted by statutory regulation or exceeds the permitted use, you will need to obtain permission directly from the copyright holder. To view a copy of this licence, visit http://creativeco mmons.org/licenses/by/4.0/. 
Conclusions: Comparing the predicted $\mathrm{Clocal}_{\text {effluent }}=335 \mu \mathrm{g}$ alkyl sulfates $/ \mathrm{L}$ (SimpleTreat default) and a Clocal $_{\text {effluent }}=44.6 \mu \mathrm{g}$ Alkyl Sulfates $/ \mathrm{L}$ (AS-specific degradation rates) with the $10.18 \mu \mathrm{g}$ alkyl sulfates $/ \mathrm{L}$ from the adjusted monitoring data it is evident, that the EUSES calculation overestimates the AS environmental exposure by factors of $>32$ and $>4$, respectively. Taking into consideration, that only widespread uses (covering only $50 \%$ of the total AS volume) were included in the EUSES calculation, the overestimation of the default exposure by a factor of 4 is still conservative, despite the fact, that eightfold higher, substance-specific biodegradation rates were used. In conclusion, using the 2010 C12-AS REACH dossier (CAS-No. 151-21-3) as an example, it has been shown, that EUSES model exposure calculations using default biodegradation rates significantly overestimate effluent concentrations.

Keywords: Surfactants, Effluent concentrations, Predicted environmental concentration (PEC), REACH, EasyTRA, Environmental monitoring, Exposure assessment, Clocal ${ }_{\text {effluent }}$

\section{Background}

The EU chemical regulation EC/1907/2006 (REACH) [15] requires chemical companies (registrants) to register their substances at the European Chemical Agency (ECHA) to obtain the "license to operate". The information requirements as well as the deadline for registration depend on the volume (manufactured or imported) of the substance of the individual registrants. If a chemical is classified for hazardous properties for humans and/ or for the environment, the registration dossier has to include an exposure assessment. Regarding the exposure to the environment, the European Union System for the Evaluation of Substances (EUSES) is the standard assessment tool. EUSES includes an environmental fate model (partitioning between air/water/solids) as well as generic wastewater treatment plant parameters, i.e. per capita water use, number of inhabitants per WWTP, and removal rates, allowing an initial estimate of exposure and subsequent risk assessment. From a legal point of view, only a risk assessment for the registered volume per registrant is required by EU REACH law. Nevertheless, from an environmental point of view, the combined, total volume of all registrants is most relevant.

In a pro-active approach, the European surfactant and detergent industry initiated a project to conduct an EUSES-based environmental exposure assessment for the total volume of AS surfactants, and to verify if the initial EUSES assessment leads to a realistic prediction of the environmental exposure or to an over- or underestimation of the environmental concentrations of the surfactants. Verification of the EUSES environmental concentration prediction $\left(\mathrm{Clocal}_{\text {effluent }}\right.$ ) was performed by benchmarking them against recent US monitoring data, adjusted to EU frame conditions.

\section{Methods}

\section{Chemicals and tonnage collection}

For an evaluation of the EUSES modelling for AS, the most common carbon-chains (C12, C14 and C16) with the highest tonnage contribution were collected. Odd numbered C-chains (C11, C13, C15), C-chains above $\mathrm{C} 16$ and below $\mathrm{C} 10$ are less common and so do not significantly influence the total amount of AS in Europe, therefore the EUSES calculations were conducted only for $\mathrm{C} 12$, C14, and C16 homologues (for a qualitative sensitivity analysis see the "Discussion" section below).

For the chain lengths $\mathrm{C} 12, \mathrm{C} 14$ and C16 tonnages were anonymously collected from the registrants of the REACH AS consortium with a production volume of $>100 \mathrm{t} / \mathrm{a}$. The homologue distribution was collected from the following even-numbered C-chain, linear AS substances: sodium dodecyl sulfate (CAS No. 151-213); sulfuric acid, mono-C12-14-alkyl esters, sodium salts (CAS No. 85586-07-8); sulfuric acid, mono-C12-16-alkyl esters, sodium salts (CAS No. 73296-89-6); sulfuric acid, mono-C12-18-alkyl esters, sodium salts (CAS No. 6895519-1); sulfuric acid, mono-C16-18-alkyl esters, sodium salts (CAS No. 68955-20-4); sulfuric acid, mono-C1214-alkyl esters, compds. with triethanolamine (CAS No. 90583-18-9); sulfuric acid, mono-C12-14-alkyl esters, compds. with ethanolamine (CAS No. 90583-16-7); sulfuric acid, mono-C12-14-alkyl esters, ammonium salts (CAS No. 90583-11-2).

In addition, the volumes of AS as constituents of alkyl ether sulfates (AES) were collected from 15 high tonnage EU REACH registrants ( $>100 \mathrm{t} / \mathrm{a})$, as AS are constituents of AES (from incomplete ethoxylation reaction, i.e. $\mathrm{EO}=0$ ) at concentrations between $10-35 \%$ with $20 \%$ as a realistic average. The AS volumes in technical AES represents a major amount of the total AS anionic surfactants concentrations since the production volume of AES exceeds that of AS by a factor of ten [7].

All registrants of the AS consortium responded to the tonnage survey. For the AES substances, 14 of 15 registrants replied. The missing information was substituted by an average tonnage reported by all tonnage information from the AES registrants.

The tonnages (from 2016) reported by the various companies were summed leading to a total tonnage of $\sim 178,400 \mathrm{t}$ (Table 1 ). 
Table 1 Overview tonnage per chain length

\begin{tabular}{lccrr}
\hline Chain length & C 12 & C 14 & C 16 & Overall \\
\hline AS (t/a) & 45,280 & 15,793 & 5200 & 66,273 \\
AES (t/a) & 82,973 & 28,689 & 496 & 112,158 \\
Total (t/a) & 128,253 & 44,482 & 5696 & 178,431 \\
\hline
\end{tabular}

\section{Use pattern}

The tonnage information for the C12, C14 and C16 AS were assigned to the different uses as reported to ECHA in the C12 AS, Na (CAS-No. 151-21-3), registration dossier of 2010 (Table 2). Use information was obtained from the latest use maps provided by the relevant industry sector associations. The main application fields of AS are the household/ cleaning sector (AISE), the personal care sector (Cosmetics Europe), the construction sector (EFCC) and the polymer dispersion and latex sector (EPDLA). All relevant sectors including the tonnage distribution are shown in Table 2.

For the tonnage distribution within the different sectors the approach sector tonnage=tonnage formulation steps $=$ tonnage end uses (industrial, professional, consumer) was used. Within the end uses a further distribution was considered. It was estimated that $60 \%$ of the sector tonnage will be consumed at the industrial scale, $30 \%$ at the professional scale, and $10 \%$ by consumers. For household/cleaning and personal care application, an equal distribution factor was used. Professionals and consumers will mainly have access to these chemical products. For the personal care sector an industrial use is not applicable. In conclusion, the tonnage of this sector was split equally between the professional and consumer applications (Fig. 1). A detailed overview is provided in Additional file 1.

\section{US Monitoring data}

A US monitoring campaign was conducted in 2016 by McDonough et al., which collected grab effluent samples from 44 wastewater treatment plants (WWTPs) across the US to generate statistical distributions of effluent concentrations for various anionic surfactants, including AS. The mean concentrations for AS, AES, linear alkylbenzene sulfonates (LAS) and methylestersulfonate (MES) were $5.03 \pm 4.5,1.95 \pm 0.7,15.3 \pm 19$, and $0.35 \pm 0.13 \mu \mathrm{g} / \mathrm{L}$, respectively. All data are publicly available [11].

\section{Extrapolation factor US/EU}

For comparison to the US monitoring data an US/EU extrapolation factor was established. This factor was used to adjust for demographic and possible technological differences between the US and EU situations. This extrapolation factor was based on three key indicators: US:EU per capita chemical use (AS), US:EU per capita water use, and US:EU WWTP efficiency ratio.

Consumption of alkyl sulphate in the US (as established in the Waterborne Report, 2018 [19]) was equated with the manufactured tonnages in the EU (as established in the REACH consortium by a confidential survey among the EU manufacturers). To calculate an average US:EU per capita chemical use ratio, the collected tonnages (US: 96,000 t/a [7]; EU: 178,431 t/a) were divided by the number of inhabitants. Assuming 327 Million inhabitants

Table 2 Distribution of tonnage to sector associations for chain length C12, C14, C16

\begin{tabular}{|c|c|c|c|c|}
\hline Sector association & Percentage of total tonnage (\%) & Tonnes per sector $\mathrm{C} 12$ & Tonnes per sector $\mathrm{C} 14$ & $\begin{array}{l}\text { Tonnes } \\
\text { per sector } \\
\text { C16 }\end{array}$ \\
\hline AISE & 32.26 & 41,372 & 12,515 & 1,811 \\
\hline ATIEL & 1.61 & 2069 & 536 & 91 \\
\hline CEPE & 0.16 & 207 & 125 & 9 \\
\hline ESVOC & 0.16 & 207 & 125 & 9 \\
\hline COSMETIC EUROPE & 16.13 & 20,686 & 8,939 & 906 \\
\hline ECPA & 8.06 & 10,343 & 1,788 & 453 \\
\hline EFCC & 16.13 & 20,686 & 8,939 & 906 \\
\hline EPDLA & 16.13 & 20,686 & 8,939 & 906 \\
\hline ETRMA & 0.16 & 207 & 72 & 9 \\
\hline FEICA & 0.81 & 1034 & 447 & 45 \\
\hline TEGEWA & 0.16 & 207 & 179 & 91 \\
\hline FERTILIZER EUROPE & 8.06 & 10,343 & 1,788 & 453 \\
\hline PPRM & 0.16 & 207 & 89 & 9 \\
\hline Total & 100 & 128,253 & 44,482 & 5696 \\
\hline
\end{tabular}




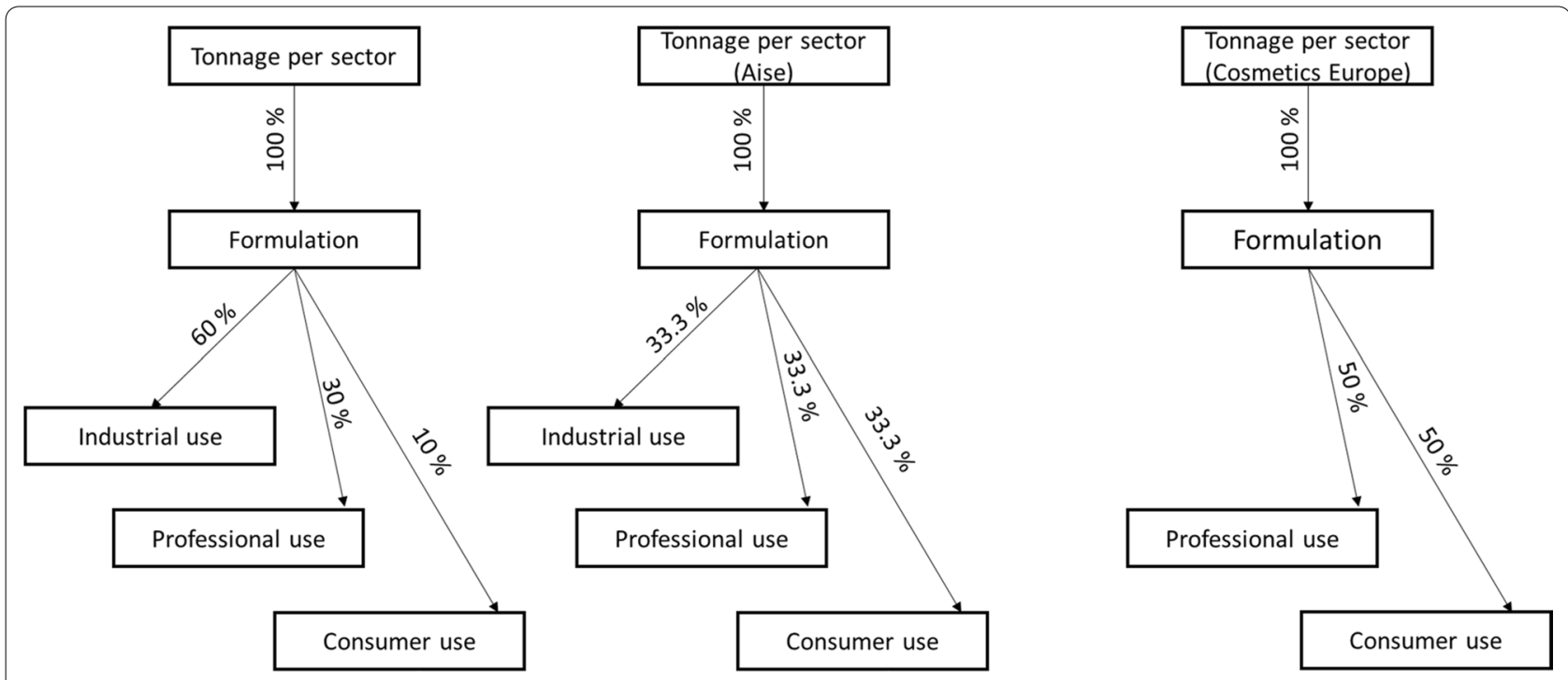

Fig. 1 Tonnage distribution approach for the different sector associations (use maps)

(2018) for the US [8] and 512 Million inhabitants (2018) for the EU [3]. In the US each inhabitant uses on average $294 \mathrm{~g}$ AS per year (0.81 g/day), whereas in the EU, each inhabitant uses $348 \mathrm{~g}$ AS per year $(0.95 \mathrm{~g} /$ day $)$. Therefore, for the US:EU per capita chemical use a ratio of 1:1.2 was established, i.e. an EU inhabitant uses 1.2 times more AS then an US inhabitant.

Per capita water use in the US were taken from the US EPA Clean Watersheds Needs Survey 2012 [18]. The survey included data from over 13,000 municipal WWTPs in the US With the iSTREEM model [19] the water per capita use was calculated by dividing the facility flow by the population served. The discharge rate varied considerably between the different facilities. The median per capita use of $406 \mathrm{~L} /$ day, which was considered as the most representative, was used for the US:EU comparison. The EUSES model considers as a standard input $200 \mathrm{~L}$ per capita per day. This amount is slightly higher than the estimated weighted European Union average of $186 \mathrm{~L} /$ capita/day [19] by using data for each member state. Nevertheless, the value of $200 \mathrm{~L} /$ capita/day was considered as reasonable for the US:EU per capita ratio. $200 \mathrm{~L}$ per capita per day (EU) compared to $406 \mathrm{~L}$ per capita per day (US) resulted in an US:EU ratio of $\sim 2: 1$. In other words, in Europe the WWTP effluents are 2 times more concentrated compared to the US.

In general, most of the existing WWTPs in the EU (88.7\%, [2] and the US (86\% according to Kapo [9]) use and rely on the activated sludge process for domestic waste water treatment, where microorganisms mineralize non-recalcitrant organic pollutants to water and carbon dioxide, or degrade/transform them to acceptable forms, like microbial biomass [2, 12, 17] or the EU and the US an equivalent treatment efficiency was assumed (US:EU =1).

Overall, US:EU extrapolation factor of 1.2 (per capita AS consumption) $\times 2.0$ (dilution in effluent) $\times 1.0$ (WWTP efficiency) $=2.4$ was estimated for the comparison. Thus, one would expect 2.4 times higher concentrations in the $\mathrm{EU} \mathrm{Clocal}_{\text {effluent }}$ than reported by McDonough et al. [11] for the US effluents.

\section{Modelling approach}

Clocal $_{\text {effluent }}$ concentration were calculated by specific environmental release categories (spERCs) from industry associations (use maps) whenever applicable. For applications with no spERCs, the default release factors for the environmental release categories (ERC) were used [1].

EUSES was used for the modelling of the EU concentrations in the WWTP effluent $\left(\right.$ Clocal $\left._{\text {effluent }}\right)$. Although under EU REACH only the individual annual production volumes per legal entity per manufacturer are uses as the basis for the environmental exposure and risk assessment, in this project the total combined production volume of AS (as such and as a component of AES) was used for EUSES modelling.

EUSES is the standard Tier I tool for exposure calculations of industrial chemicals. The tool forms the basis for all further exposure modelling tools developed within the context of EU REACH like ECETOC TRA, Chesar and EasyTRA (EasyTRA is a commercial software offered by Jansen-Systems, 42799 Leichlingen, Germany).

For the estimation of the AS Clocal effluent $_{\text {concentration }}$ in the EU, the EasyTRA tool by Jansen Systems GmbH 
was used. In cooperation with Jansen-Systems $\mathrm{GmbH}$ an extension of the tool was developed to display the average $\mathrm{Clocal}_{\text {effluent }}$ concentrations directly.

The default EUSES daily discharge rate of $2000 \mathrm{~m}^{3} /$ day for a municipal WWTP (200 L wastewater per capita for a population of 10,000 inhabitants) remains unchanged for the Clocal ${ }_{\text {effluent }}$ calculations [1].

For each chain length $(\mathrm{C} 12, \mathrm{C} 14, \mathrm{C} 16)$ a substance data set was generated in the tool. The environmental behaviour of the AS surfactants, the physico-chemical properties: molecular weight, vapour pressure, water solubility, partition coefficient and adsorption of the representative homologues AS C12, Na (CAS No. 151-21-3); AS C14, $\mathrm{Na}$ (CAS No. 1191-50-0) and C16, Na (CAS No. 1120-012 ) were taken into account (Table 3).

Further, substance-specific biodegradation rates were used in a second step, where appropriate, e.g. increased biodegradation rates (192 per day instead of the default of 24 per day for WWTP) to evaluate, if this higher tier approach leads to more realistic predictions.

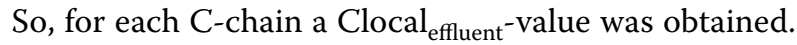
In the end, the three $\mathrm{Clocal}_{\text {effluent }}$-value were summed to yield an overall AS Clocal effluent $^{-v a l u e, ~ w h i c h ~ i s ~ t h e n ~ c o m-~}$ pared to the US monitoring result.'

The uses for the assessment were based on information by the sector associations use maps and were distributed amongst the sectors and the single uses as described in point 'use pattern'. For industrial sites no further split was made to estimate the local site tonnage.

For the estimation of the local amount for widespread uses, the EUSES model already considers a default fraction of the main local source of $5.5 \mathrm{E}-7$ year/day to break down the overall tonnage per application to the amount used at the local scale. This reduction factor includes the fraction of the "tonnage for the use" used in the region (0.1), the fraction of the regional tonnage (0.0005) used in the standard town $(10,000$ inhabitants) compared to the number of inhabitants in the region $(20,000,000$ inhabitants) and the number of days in a year (365 days). An additional default safety factor of 4 is applied by EUSES to cover temporary peaks. Based on the information from the specific environmental release categories (spERCs) for AISE and Cosmetics Europe a fraction of EU tonnage used in region of 0.04 (AISE) or 0.053 (Cosmetics Europe) and a fraction of the regional tonnage used locally of 0.00075 without a safety factor for seasonal peaks was used [13].

ASs are readily biodegradable according to the OECD criteria (see REACH dossiers). Solely based on the substance properties modelled elimination rates by SimpleTreat [16] showed for all AS chain lengths an elimination in the sewage treatment plant WWTP) greater than 90\%. Representative AS degradation simulation studies (Potoms [14] and Federle \& Itrich $[4,5]$ ) indicated higher $(8 \times)$ degradation rates compared to the default assumptions used in SimpleTreat model predictions. Therefore, in accordance with the $2010 \mathrm{EU}$ REACH registration dossiers, a degradation rate of 192 per day instead of 24 per day was used in the tier 2 step for the Clocal $_{\text {effluent }}$ estimation.

The Clocal $_{\text {effluent }}$ estimation for the default-and for the AS-specific (tier 2) degradation rates were used for benchmarking against the US monitoring data. Furthermore, for the actual modelling purposes of $\mathrm{Clocal}_{\text {effluent }}$ in the EU, only the $\mathrm{Clocal}_{\text {effluent }}$ from widespread consumer and professional uses were considered. Uses which do not lead to emissions to WWTPs, i.e. direct application to soil, were not further considered for the $\mathrm{Clocal}_{\text {effluent }}$ calculation.

The restriction to the widespread consumer used is scientifically justified, as only the emissions from widespread consumer uses are relevant for all EU WWTPs. Only the Clocal effluent $_{\text {from widespread consumer uses }}$ is directly comparable to the Clocal effluent $_{\text {established by }}$ [11]. In other words, inclusion of the industrial end uses, which are generally considered point source emissions, would result in seemingly higher average emissions. Regarding the working hypothesis of this paper (EUSES tier 1 calculations result in unrealistic high Clocal $_{\text {efluent }}$ values), exclusion of industrial end uses is the worstcase scenario, as it tends to reduce the overestimation of Clocal $_{\text {effluent }}$ by EUSES. Therefore, it was decided to limit the $\mathrm{Clocal}_{\text {effluent }}$ assessment to the widespread consumer uses.

Table 3 Substance properties ( taken from the REACH dossiers)

\begin{tabular}{|c|c|c|c|c|c|}
\hline $\begin{array}{l}\text { Physico-chemical properties } \\
\text { Homologues }\end{array}$ & Molecular weight $(\mathrm{g} / \mathrm{mol})$ & Vapour pressure $(\mathrm{Pa})$ & Water solubility (g/l) & Partition coefficient (log Kow) & $\begin{array}{l}\text { Adsorption } \\
\text { coefficient (log } \\
\text { Кос) }\end{array}$ \\
\hline $\begin{array}{l}\text { AS C12, Na } \\
\text { CAS: 151-21-3 }\end{array}$ & 288.38 & 0.18 & 130 & -2.03 & 2.5 \\
\hline $\begin{array}{l}\text { AS C14, Na } \\
\text { CAS: } 1191-50-0\end{array}$ & 316.43 & $<10$ & $\sim 100$ & 2.19 & 3.13 \\
\hline $\begin{array}{l}\text { AS C16, Na } \\
\text { CAS: } 1120-01-0\end{array}$ & 344.49 & $<20$ & 1.54 & 2.19 & 3.515 \\
\hline
\end{tabular}


Limitation to the widespread consumer uses covers $118,034 \mathrm{t}$ compared to the total use amount of 178,400 t. Uses with direct application to soil, i.e. plant protection products (ECPA) and fertilizers (Fertilizer Europe), were not considered for the Clocal $_{\text {effluent }}$ calculation. These uses without connection to any WWTP account for 20,145 t of AS. Overall, the tonnage assessed for the Clocal $_{\text {effluent }}$ evaluation was 97,889 t ( 100,000 t). A qualitative sensitivity analysis of the effect of this simplification on the general conclusion of this publication is given in the Results and discussion sections below.

\section{Results and discussion}

Collection of AS volumes was conducted within the $\mathrm{REACH}$ consortium by means of a trustee, in order to comply with the EU competition law. As AS comprise a significant proportion of AES (from incomplete ethoxylation reaction, i.e. $\mathrm{EO}=0$ ), volumes were also collected for AS as constituents of AES. Data collection was limited to EU REACH phase 1 (production volume per manufacturer per year $>1,000 \mathrm{t}$ ) and phase 2 (100$1,000 \mathrm{t})$ registered substances. A total maximum volume (2016) handled annually in Europe of 178,400 t AS was established. This volume comprised $\sim 128,200$ t C12 AS, $\sim 44,500$ t C14 AS and 5,700 t C16 AS homologues. Assignment of the proportion of AS to the different uses was performed according to the use pattern of C12 AS, volume-wise this is the most important AS, assuming equal use patterns for all AS homologues. The EUSES calculation was limited to widespread (professional and consumer) uses which are connected to WWTP, covering a total volume of $\sim 100,000$ t AS homologues (Table 4).
This widespread volume comprised 70,361 t C12 AS, 24,403 t C14 AS and 3124 t C16 AS homologues. From the EUSES calculation, a total Clocal ${ }_{\text {effluent }}$ for the widespread uses of $44.6 \mu \mathrm{g} / \mathrm{L}$ (Table 5) was obtained. C12 AS contributed around $74 \%$ of the total Clocal $_{\text {effluent }}$ concentration. C14 AS had a share of $23 \%$. The impact of C16 AS was minor with only a share of $3 \%$ of the total concentration.

Household/cleaning and personal care products (AISE and Cosmetics Europe) made the highest tonnage contribution and by far the highest Clocal $_{\text {effluent }}$ concentration. In both sectors AS are mainly used in down-the-drain/wash-off products with a considered release of $100 \%$ into the municipal/domestic sewage system. Both sectors, independent of the degradation rates, together contributed $\sim 97 \%$ of the total Clocal $_{\text {effluent }}$ concentration but with only $69 \%$ of the tonnage.

The household/cleaning sector accounted for $209 \mu \mathrm{g} / \mathrm{L}$ (default degradation rates) and 26,8 $\mu \mathrm{g} / \mathrm{L}$ (AS-specific degradation rates) (C12 AS: $154 \mu \mathrm{g} / \mathrm{L} / 19,8 \mu \mathrm{g} / \mathrm{L} ; \mathrm{C} 14$ AS: $50.5 \mu \mathrm{g} / \mathrm{L} / 16,3 \mu \mathrm{g} / \mathrm{L}$; C16 AS: $5.2 \mu \mathrm{g} / \mathrm{L} / 0,7 \mu \mathrm{g} / \mathrm{L})$, i.e. about $60 \%$ of the total Clocal $_{\text {effluent }}$ concentration. The personal care sector accounted around for $37 \%$ of the total Clocal effluent $_{\text {concentration with only } 29 \% \text { of the total }}$ tonnage. All other sectors as described in Table 2 showed only a negligible impact on the $\mathrm{Clocal}_{\text {effluent }}$ concentrations. With $31 \%$ of the total tonnage, the EUSES calculation estimated Clocal $_{\text {effluent }}$ concentrations of $10.86 \mu \mathrm{g} / \mathrm{L}$ and $1.34 \mu \mathrm{g} / \mathrm{L}$, which reflects only $3 \%$ of the total Clocal $_{\text {effluent }}$ concentration. The usage of AS in these sectors will not lead to an effluent release of $100 \%$. AS from

Table $4 \mathrm{Clocal}_{\text {effluent }}$ (default SimpleTreat degradation rates) modelling results EUSES for C12, C14, C16

\begin{tabular}{|c|c|c|c|c|c|c|c|c|}
\hline & Total tonnage $(\mathrm{t})$ & $\begin{array}{l}\text { Total } \\
\text { Clocal }_{\text {eff. }} \\
(\mu \mathrm{g} / \mathrm{L})\end{array}$ & AISE tonnage $(t)$ & $\begin{array}{l}\text { AISE } \\
\text { Clocal }_{\text {eff. }} \\
(\mu \mathrm{g} / \mathrm{L})\end{array}$ & $\begin{array}{l}\text { Cosmetics } \\
\text { Europe } \\
\text { tonnage (t) }\end{array}$ & $\begin{array}{l}\text { Cosmetics } \\
\text { Europe } \\
\text { Clocal }_{\text {eff. }}(\mu \mathrm{g} / \mathrm{L})\end{array}$ & $\begin{array}{l}\text { Other sectors } \\
\text { tonnage }(\mathrm{t})\end{array}$ & $\begin{array}{l}\text { Others sectors } \\
\text { Clocal }_{\text {eff. }}(\mu \mathrm{g} / \mathrm{L})\end{array}$ \\
\hline C12 & 70,361 & 242.9 & 27,581 & 154 & 20,686 & 81 & 22,094 & 7.85 \\
\hline C14 & 24,402 & 83.5 & 9,566 & 50.5 & 7174 & 30.2 & 7662 & 2.73 \\
\hline C16 & 3,125 & 8.6 & 1,225 & 5.2 & 919 & 3.1 & 981 & 0.28 \\
\hline Total & 97,889 & 335 & 38,362 & 209.7 & 28,779 & 114.3 & 30,737 & 10.86 \\
\hline
\end{tabular}

Table 5 Clocal $_{\text {effluent }}$ (AS-specific degradation rates) modelling results EUSES for C12, C14, C16

\begin{tabular}{|c|c|c|c|c|c|c|c|c|}
\hline & Total tonnage $(\mathrm{t})$ & $\begin{array}{l}\text { Total } \\
\text { Clocal }_{\text {eff. }} \\
(\mu \mathrm{g} / \mathrm{L})\end{array}$ & AISE tonnage $(t)$ & $\begin{array}{l}\text { AISE } \\
\text { Clocal }_{\text {eff. }} \\
(\mu \mathrm{g} / \mathrm{L})\end{array}$ & $\begin{array}{l}\text { Cosmetics } \\
\text { Europe } \\
\text { tonnage }(t)\end{array}$ & $\begin{array}{l}\text { Cosmetics } \\
\text { Europe } \\
\text { Clocal }_{\text {eff. }}(\mu \mathrm{g} / \mathrm{L})\end{array}$ & $\begin{array}{l}\text { Other sectors } \\
\text { tonnage }(t)\end{array}$ & $\begin{array}{l}\text { Others sectors } \\
\text { Clocal }_{\text {eff. }}(\mu \mathrm{g} / \mathrm{L})\end{array}$ \\
\hline C12 & 70,361 & 33 & 27,581 & 19.8 & 20,686 & 12.2 & 22,094 & 1 \\
\hline C14 & 24,402 & 10.4 & 9,566 & 6.3 & 7174 & 3.8 & 7662 & 0.3 \\
\hline C16 & 3,125 & 1.19 & 1,225 & 0.7 & 919 & 0.4 & 981 & 0.04 \\
\hline Total & 97,889 & 44.6 & 38,362 & 26.8 & 28,779 & 16.4 & 30,737 & 1.34 \\
\hline
\end{tabular}


technical application will be mainly disposed as waste after usage (e.g. motor oil).

The eight times higher degradation rates for AS (192 per day compared to 24 per day) resulted in around $335 \mu \mathrm{g} / \mathrm{L} / 44.6 \mu \mathrm{g} / \mathrm{L} \approx 7.5$ times lower total Clocal $_{\text {effluent }}$ concentrations.

The study "Evaluation of anionic surfactant concentrations in US effluents and probabilistic determination of their combined ecological risk in mixing zones" published by McDonough et al. [11] included a comprehensive US monitoring dataset (i.e. average local WWTP effluent concentrations) for high-volume anionic surfactants including AS and AES. These data serve as a plausibility check for the calculated EU average local WWTP effluent concentrations. The US monitoring data show a mean effluent concentration of $4.24 \mu \mathrm{g}$ alkyl sulfates/L ( $\sum \mathrm{C} 12, \mathrm{C} 14, \mathrm{C} 16$ homologues). Taking into account the different annual per capita AS use (including AS from AES) in the US (295 g) and the EU (348 g), the daily per capita water use (EU $200 \mathrm{~L}$, US $408 \mathrm{~L}$ ), and the WWTP efficiency in the EU and the US (comparable), a US to EU adjustment factor of 2.4 has been established. Application of the adjustment factor to the US monitoring data results in a calculated EU mean effluent concentration of $10.18 \mu \mathrm{g}$ alkyl sulfates/L ( $\sum \mathrm{C} 12, \mathrm{C} 14, \mathrm{C} 16$ homologues). Modelled concentrations are expected to be in that range.

Benchmarking the EU adjusted US monitoring data with the modelled exposure concentrations, a difference between the modelling and the monitoring became clear. Comparing the modelled effluent concentration $\left(\sum \mathrm{C} 12\right.$, C14, C16 homologues) of $335 \mu \mathrm{g} / \mathrm{L}$ and $44.6 \mu \mathrm{g} / \mathrm{L}$ with the adjusted US monitoring data $=10.18 \mu \mathrm{g} / \mathrm{L}$, showed that the EUSES modelled concentration with the default degradation rates was 32.9 times higher than the adjusted monitoring data. Modelling with AS-specific degradation rates resulted in 4.4 times higher $\mathrm{Clocal}_{\text {effluent }}$ concentrations. Even the $\mathrm{Clocal}_{\text {effluent }}$ concentration of individual sectors, household/cleaning sector $(26.8 \mu \mathrm{g} / \mathrm{L})$ and personal care sector $(16.4 \mu \mathrm{g} / \mathrm{L})$, was about twice as high as the monitoring data despite the AS-specific degradation rates.

Both, the adjusted monitoring data and the modelling approach are subject to considerable uncertainties. It could be questioned if the monitoring data from US could be directly transferred to the EU by applying an adjustment factor of 2.4 based on the substance use rate, per capita water use and WWTP efficiency. Therefore, the US monitoring data should be seen as a plausibility check, rather than a validation of the calculated Clocal $_{\text {efluent }}$ concentrations.

However, a recent expert report from a German sewage treatment plant (WWTP) effluent monitoring programme sponsored by the German Environment Agency [6] reported an average effluent concentration of $0.6 \mu \mathrm{g} / \mathrm{L}$ and a maximum effluent concentration of $1.9 \mu \mathrm{g} / \mathrm{L}$ for AES. The reported concentration was slightly lower than the US monitoring data for AES ( $\varnothing$ Clocal $_{\text {effluent }}=1.95 \pm 0.7 \mu \mathrm{g} / \mathrm{L}$ ) reported by McDonough et al. [11]. Although the monitoring data relates exclusively to WWTPs in Germany, they support the low digit $\mu \mathrm{g} / \mathrm{L}$ concentration of the US monitoring data. Based on the German WWTP monitoring data, even lower concentrations of the Clocal effluent $_{\text {could be expected for }}$ AS compared to the ones derived from the adjusted US monitoring data.

The EUSES modelling has several uncertainties due to a lack of information. The tonnage collection was based on a top down approach. Tonnage was collected from all high tonnage ( $>100 \mathrm{t} /$ year) AS and AES registrants. Missing information was covered with an average amount from all lower ton registrants. Any exports or low tonnage imports $(<100 \mathrm{t} /$ year) by subsequent downstream users were not be considered to limit the effort. Regarding the working hypothesis of this paper (EUSES tier 1 calculations result in unrealistic high Clocal $_{\text {effluent }}$ values), the exclusion of imported AS quantities and the limitation to tier 1 and 2 registered volumes is a worstcase scenario, as it tends to reduce the overestimation of Clocal $_{\text {effluent }}$ values by EUSES. Further, the tonnage distribution in the single sectors was based on the C12 AS, $\mathrm{Na}$ (151-21-3) registration dossier in 2010 with a general tonnage split between the use patterns. The focus of the EUSES modelling was on the widespread uses (professional and consumers) only, although it is common that industrial application as well as widespread uses discharge into a municipal WWTP.

However, due to the missing information on the number of point sources connected to industrial sites, no robust tonnage split (fraction of the main local source) for industrial uses and formulation could be considered. Consequently, the EUSES modelling, applying a worst case, would set by default the local tonnage at an industrial site equal to the regional tonnage. Due to the combined tonnage collection from all registrants it was not realistic to assume that the regional amount for one application type would be used at a single site. In this case, such a default assumption, resulting in an unrealistically high overestimation, would not be compatible with the $\emptyset$ Clocal $_{\text {effluent }}$ comparison. For widespread uses the EUSES calculation circumvents the problem of the local use amount by applying the default fraction of the main local source (5.5E-7) and the specific fractions for AISE (8.2E-8) and Cosmetics Europe (1.1E-7). Therefore, the focus of the comparison was on the widespread uses solely, as only these uses can be assumed to be evenly distributed between all WWTP in Europe. The 
amount of $\sim 100,000 \mathrm{t}$ ( $\sum \mathrm{C} 12, \mathrm{C} 14, \mathrm{C} 16$ homologues) for widespread uses connected to a WWTP was considered as exemplary for the Clocal $_{\text {effluent }}$ estimation.

It is a well-known fact that AS are readily and rapidly biodegradable substances. Studies have shown that biodegradation rates in reality are around eight times higher $[14,5$, 6] than the degradation rates estimated by the SimpleTreat model based on the substance properties. Using the default SimpleTreat degradation rates would lead to an unrealistic overestimation of the Clocal effluent $_{\text {concentrations. The }}$ default degradation rate of 24 per day may be applicable for some readily biodegradable substances but for readily and rapidly biodegradable substances like AS, the modelling showed that the degradation rates are too conservative. This is confirmed by McAvoy et al. [10] and Freeling et al. [6], which both found equally high elimination rates for activated sludge treatment ( $98 \%)$, as we assumed in the tier 2 modelling step.

Although there are clearly numerous assumptions and simplifications in this assessment, qualitative uncertainty analysis show, that all assumptions and simplifications introduced generally tend to reduce the overestimation of Clocal $_{\text {effluent }}$ by EUSES. Regarding the working hypothesis of this paper (EUSES tier 1 calculations result in unrealis-

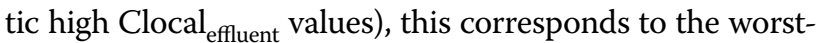
case scenario.

Overall, the described approach was considered as reasonable worst case for the $\mathrm{Clocal}_{\text {effluent }}$ comparison.

\section{Conclusions}

The evaluation strongly indicated that under the applied conditions, the EUSES calculation over-predicts the environmental exposure of AS in wastewater effluent discharges by a factor of $>32$ (EUSES default biodegradation rates) and $>4$ (substance-specific biodegradation rates as applied for exposure calculations in the EU REACH tier 1 registration dossiers). One possible explanation can be attributed to the fact, that default biodegradation rates assumed in the SimpleTreat module of EUSES are unrealistically low for readily and rapidly biodegradable substances such as AS.

Taking into consideration the fact that only EU REACH registered $\mathrm{AS} \geq 100 \mathrm{t} / \mathrm{y}$ (including $\mathrm{AES}$ containing AS) were considered and that only widespread uses were included in the EUSES calculation and that the assessment was conducted with substance-specific -8 times higher biodegradation rates, the overestimation of the exposure by a factor of 4 is still conservative.

\section{Authors' information}

MB, JD, DK, KMD, DS, KS, JW and AW are members of the ERASM Reach Reality Check Task Force. OS is an Ecotoxicologist (Contractor) working for Dr. Knoell Consultant.

\section{Availability of data and material}

The tailored EasyTRA version, displaying the average Clocal $_{\text {effluent }}$ concentrations directly, all the EasyTRA files used in the context of the publication, as well as the Waterborne report [19] will be provided by ERASM upon request.

\section{Supplementary Information}

The online version contains supplementary material available at https://doi. org/10.1186/s12302-020-00435-1.

Additional file 1. $\sum \mathrm{C} 12, \mathrm{C} 14, \mathrm{C} 16$ homologues (tonnages; Clocal $_{\text {effluent }}$ concentrations)

\section{Acknowledgement}

The authors thank the ERASM Technical Committee (Brussels) for their financial and administrative support of this study.

Further, the authors want to thank Norbert Stelter (ex Henkel KGaA, Düsseldorf, Germany, retired since March 2020) and Ricky Stackhouse (Sasol Corporation, Westlake, La. 70669, USA) for their valuable input and critical feed-back to this project.

\section{Authors' contributions}

AW was the project leader of the ERASM Reach Reality Check project. He coordinated the project and acted as focal point the communication to the consultant involved (Knoell Germany GmbH). MB, JD, DK, KMD, DS, KS, OS, JW and AW contributed with scientific expertise to the project and the publication. OS and AW drafted the manuscript. All authors read and approved the final manuscript.

\section{Funding}

The work was funded by the industry association ERASM [Environmental Risk Assessment and Management. ERASM is a joint research initiative between the industry associations CESIO (surfactants) and AISE (detergents)].

\section{Ethics approval and consent to participate}

Not applicable.

\section{Consent for publication \\ Not applicable.}

\section{Competing interests}

Although the authors (except KS and OS) work for different companies, which are competitors in the market, all authors declare that they have no competing interests regarding the content and the conclusions of this publication.

\section{Author details}

1 Knoell Germany GmbH, Konrad-Zuse-Ring 25, 68163 Mannheim, Germany. ${ }^{2}$ Henkel AG \& Co. KGaA, Henkelstraße 67, 40589 Düsseldorf, Germany. ${ }^{3}$ Innospec Limited, Oil Sites Road, Ellesmere Port, Cheshire CH65 4EY, UK. ${ }^{4}$ Sasol Germany GmbH, Paul-Baumann-Str. 1, 45772 Marl, Germany. ${ }^{5}$ rocter \& Gamble, 8700 South Mason Montgomery Road, Mason, OH 45040, USA. ${ }^{6}$ Procter \& Gamble Brussels Innovation Center, Temselaan 100, 1853 Strombeek-Bever, Belgium. 7 ACl (American Cleaning Institute), 1401 H Street, NW, Ste 700, Washington, DC 20005, USA. ${ }^{8}$ Shell Health, Carel van Bylandtlaan 16, 2596 HR The Hague, The Netherlands. ${ }^{9}$ BASF Personal Care and Nutrition $\mathrm{GmbH}$, Henkel Str. 67, 40589 Düsseldorf, Germany. 
Received: 10 August 2020 Accepted: 27 November 2020

Published online: 07 January 2021

\section{References}

1. European Chemicals Agency 2016 (2016) Guidance on information requirements and chemical safety assessment chapter R.16: environmental exposure assessment. Helsinki: ECHA.

2. European Commission (EC) (2012) EU wide monitoring survey on waste water treatment plant effluents. http://publications.jrc.ec.europa.eu/ repository/bitstream/JRC76400/lb-na-25563-en.pdf.pdf. Accessed May 2020.

3. Eurostat (7/10/2018): EU population up to nearly 513 million on 1 January 2018. Increase driven by migration. https://ec.europa.eu/eurostat/docum ents/2995521/9063738/3-10072018-BP-EN.pdf/ccdfc838-d909-4fd8b3f9-db0d65ea457f. Accessed Dec 2019.

4. Federle TW, Itrich NR (1996a) Aerobic die-away of tetradecyl sulfate (X0556.01R) in activated sludge from Sycamore sewage treatment plant. Testing laboratory: Environmental Science Department, Ivorydale Technical Center, Cincinnati, OH 45217. Report no.: E95-023. Owner company: Procter \& Gamble Eurocor, Strombeek Bever, Belgium. Study number: 35966. Report date: 1996-01-08.

5. Federle TW, Itrich NR (1996b) Fate of surfactants in river water. Testing laboratory: Environmental Science Department, Ivorydale Technical Center, Cincinnati, Ohio 45217. Report No.: E94-009. Owner company: Procter \& Gamble Eurocor, Strombeek Bever, Belgium. Study number: 35563. Report date: 1996-01-08.

6. Freeling F, Alygizakis NA, von der Ohe PC, Slobodnik J, Oswald P, Aalizadeh R et al (2019) Occurrence and potential environmental risk of surfactants and their transformation products discharged by wastewater treatment plants. Sci Total Environ 681:475-487. https://doi.org/10.1016/j. scitotenv.2019.04.445

7. IHS (2016) Detergent alcohols, chemical economics handbook. https:// www.ihs.com/products/detergent-alcohols-chemical-economics-handb ook.html

8. International Monetary Fund (IMF) (2019) World Economic Outlook (October 2019), Population. https://www.imf.org/external/datamapper/ LP@WEO/USA? year=2018. Accessed Oct 2019.

9. Kapo K, McDonough K, Federle T, Dyer S, Vamshi R (2014) Development of a reference base of mixing zone and drinking water intake dilution factor and wastewater generation distributions to enable probabilistic assessment of down-the-drain consumer product chemicals in the US. Sci Tot Environ 518-519:302-309

10. McAvoy DC, Dyer SD, Fendinger NJ, Eckhoff WS, Lawrence DL, Begley WM (1998) Removal of alcohol ethoxylates, alkyl ethoxylate sulfates, and linear alkylbenzene sulfonates in wastewater treatment. Environ Toxicol Chem 17(9):1705-1711. https://doi.org/10.1002/etc.5620170909

11. McDonough K, Casteel K, Itrich N, Menzies J, Belanger S, Wehmeyer K, Federle T (2016) Evaluation of anionic surfactant concentrations in US effluents and probabilistic determination of their combined ecological risk in mixing zones. Sci Total Environ 572(2016):434-441

12. Milieu, WRC, RPA (2013) Environmental, economic and social impacts of the use of sewage sludge on land. Final Report-Part III: Project Interim Reports. Service contract No 411 070307/2008/517358/ETU/G4. http:// ec.europa.eu/environment/archives/waste/sludge/pdf/part_iii_repor t.pdf. Accessed May 2020

13. Price OR, Hughes GO, Mason PJ, Roche NL (2010) Improving emission estimates of ingredients used in home and personal care products for use in EU risk assessments. Integr Environ Assess Manag. 6(4):677-684

14. Potoms H (1992) A test for detecting recalcitrant metabolites on three surfactants. Not applicable. Testing laboratory: ETC, R\&D Analytical Laboratory. Report no.: E 2089-11 H. Potoms Owner company: Procter \& Gamble Eurocor, Strombeek Bever, Belgium. Study number: 35882. Report date: 1992-05-14.

15. Regulation (EC) No 1907/2006 of the European Parliament and of the Council of 18 December 2006 concerning the Registration, Evaluation, Authorisation and Restriction of Chemicals (REACH), establishing a European Chemicals Agency, amending Directive 1999/45/EC and repealing Council Regulation (EEC) No 793/93 and Commission Regulation (EC) No 1488/94 as well as Council Directive 76/769/EEC and Commission Directives 91/155/EEC, 93/67/EEC, 93/105/EC and 2000/21/EC (Text with EEA relevance)

16. Struijs J (2014) SimpleTreat 4.0: a model to predict fate and emission of chemicals in waste water treatment plant: background report describing the equations. RIVM Report 601353005. RIVM. Bilthoven, The Netherlands

17. The World Bank (2015) East Asia and Pacific Wastewater to Energy Processes: a Technical Note for Utility Managers in EAP countries. Report No: ACS13221. http://documents.worldbank.org/curated/en/4899414681 88683153/pdf/ACS13221-v1-Revised-Box393171B-PUBLIC-Wastewater -to-Energy-Report-Main-Report.pdf. Accessed May 2020.

18. USEPA (2016) Clean Watersheds Needs Survey 2012 Report to Congress. Office of Wastewater Management, Washington, DC

19. Waterborne Environmental (2018) Feasibility Assessment, Final Report REACH Reality Check Project (Phase II, Step 1), Waterborne Study Number 312.02

\section{Publisher's Note}

Springer Nature remains neutral with regard to jurisdictional claims in published maps and institutional affiliations.

\section{Submit your manuscript to a SpringerOpen ${ }^{\circ}$ journal and benefit from:}

- Convenient online submission

- Rigorous peer review

- Open access: articles freely available online

- High visibility within the field

Retaining the copyright to your article

Submit your next manuscript at springeropen.com 